\section{In sequence}

\section{Gunnar von Heijne}

Protein Sequence \& Data Analysis. Chairman of the executive editors $A$. Tsugita. Springer-Verlag. 6/yr. DM 610, $\$ 353$.

Most readers of Protein Sequence \& Data Analysis are probably not aware that the cover logo depicts the amino-terminal sequence of tetanus toxin. It is not clear to me whether some symbolic significance should be attached to this choice; but it was a rather unhappy one, in that this protein sequence is derived from cDNA itself as the bulwark of the protein sequencers in an ocean of DNA-jocks.

The opening editorial states that the journal has three main objectives: to provide a forum for the publication of pure protein-sequence data that would not readily be accepted by other journals; to provide a medium for the advancement of theoretical sequence data analysis; and to print recent entries from the Protein Identification Resource (PIR) Protein Sequence Database as a service to sciencomputerized databanks.

Judging by the number of pages devoted data even though the journal portrays tists who do not have ready access to

to each of these objectives, the editors seem to have opted for a 1:1:1 ratio. Thus a typical issue will contain something like five full papers, one short note and 60-70 pages of PIR entries.

Overall, the scientific standard of the papers is on a par with those found in such publications as European Journal of Biochemistry, Nucleic Acids Research, Computer Applications in the Biosciences (CABIOS) and Journal of Molecular Evolution. Protein Sequence \& Data Analysis may thus evolve to become a focal point for work dealing with the experimental and theoretical analysis of protein sequences per se, although papers of this kind are certainly also found in many of the main biochemical journals.

On a more critical note, I think that the large space devoted to PIR databank entries could be more profitably filled in other ways - indeed, if one can afford a subscription to Protein Sequence \& Data Analysis one should probably first think of spending the money on a cheap PC equipped with the appropriate software and databanks. After all, it was my computer, not the journal, that identified the tetanus toxin logo for me.

Gunnar von Heijne is in the Department of Molecular Biology, Karolinska Institute, Center for Biotechnology, Novum, S-141 52 Huddinge, Sweden.

\section{Defence work}

\section{Fred S. Rosen}

Joumal of Autoimmunity. Editor J. F. Bach. Academic. 6/yr. UK£98, elsewhere $\$ 186$ (institutional); UK $£ 49$, elsewhere $\$ 93$ (personal).

Autoimmunity. Editor Terence J. Wilkin. Harwood. 4 issues/volume. \$222 (institutional): $\$ 144$ (university library); $\$ 72$ (personal).

Current Opinion in Immunology. Editors I. M. Roitt, P. Marrack and F. Alt. Current Science. 6/yr. North America \$200, elsewhere 1120 (institutional); North America \$95, elsewhere $£ 55$ (personal). Regional Immunology. Editor-in-chief J. Wayne Streilein. Wiley. 6/yr. US $\$ 115$, elsewhere $\$ 166$ (institutional); US $\$ 80$, elsewhere $\$ 110$ (personal).

DURING the past decade immunologists have made enormous progress in undertanding the molecular basis of the immune response. The $\mathrm{T}$-cell antigen receptors have been discovered and the genes encoding them have been mapped and sequenced. The mechanism whereby an antigen is converted into an immunogen has been elucidated. Crystallographic pictures have been obtained of class I histocompatibility molecules and they for example the proceedings of the First International Meeting on Immunointervention in Autoimmune Diseases appeared within six months of the meeting.

This journal appears to fill a need in an active field of research. With a modest personal subscription rate, it is good value for both researchers and clinicians. The other new entry into this arena, Autoimmunity, inspires no such confidence. Edited by T. J. Wilkin of Southampton General Hospital, it contains original submissions and also book reviews, invited reviews, brief meeting reports and hypotheses. But in both price and quality of the contents it does not fare well in comparison with Journal of Autoimmunity.

It is a daunting task to be familiar with the vast panoply of immunological literature. The publisher, Current Science, developed the innovative idea of scanning over 100 journals in immunology, publishing a list of the articles culled, and grouping them into discrete subjects such as innate immunity, immune response, immunodeficiency and so on. An authority in each field chooses several commentators who discuss the most interesting findings, and highlight and summarize the relevant articles.

Current Opinion in Immunology, the vehicle for this enterprise, succeeds only partially. There are two obvious prerequisites in such a vast undertaking. One is that the scanning of the journals must be complete and knowledgeably performed. I found several notable omissions, which led me to the conclusion that the job was not well done. The other is that the taste, authority and breadth of knowledge of the commentators have to be of the highest order. The reviews are wanting in this regard also.

Every other month two subjects are covered, such as immunity to infection and immunodeficiency or atopic allergy and autoimmunity. The format of the journal is pleasing and easy to read, and informative, original figures are reproduced. Each brief review is followed by a bibliography of relevant papers, which are graded by the reviewer as to their relative importance. After this appears a presumably complete list of the world literature on the subject discussed.

Overall supervision of the contents is not all it might be. I found three different discussions of the leukocyte adhesion deficiency in three separate issues; although this is a fascinating genetic defect, its overrepresentation is an example of imbalance in the journal's contents.

It was obviously an instance of monumental hubris to undertake this task. Its conceiver certainly ran the risk of invoking the wrath of the gods - or of those omitted in the scanning process. Current Opinion in Immunology is great 